\title{
A SÍNTESE DA TOBERMORITA E SUA APLICAÇÃO NA ENGENHARIA DE MATERIAIS
}

Y.Kihara ${ }^{1}$

$\mathrm{O}$ mineral tobermorita $\left(\mathrm{Ca}_{5}(\mathrm{OH})_{2} \mathrm{Si}_{6} \mathrm{O}_{16} \cdot 4 \mathrm{H}_{2} \mathrm{O}\right)$ foi descrito por HENDLEY (1880) em Tobermory, Escócia (CLARINGBALL \& HEY, 1953) e ocorre em região de contato entre diabásio e calcário, associado com a scawtita $\left(\mathrm{Ca}_{7}\left(\mathrm{Si}_{6} \mathrm{O}_{18}\right)\left(\mathrm{CO}_{3}\right) \cdot \mathrm{H}_{2} \mathrm{O}\right)$, preenchendo amígdalas em rochas larníticas do contato (McCONNELL, 1954).

No processo de hidratação do cimento portland, em condições de cura hidrotermal (autoclave), a cinética de hidratação do cimento é acelerada, promovendo a formação de produtos de hidratação mais desenvolvidos e cristalizados, distintos daqueles normalmente observados em condições normais de hidratação. $O$ principal produto de reação é o silicato de cálcio hidratado, com estrutura similar ao mineral tobermorita, responsável pelo desenvolvimento das resistências mecânicas (RAMCHANDRAN, 1965).

A hidratação acelerada do cimento, por autoclave, permitiu o desenvolvimento de vários produtos cimentíceos, dentre os quais se destaca o concreto celular autoclavado. É um concreto leve, homogêneo, de natureza siliciosa e com estrutura granular fina e porosa, produto de uma hidratação acelerada de mistura de cimento portland, cal, areia e incorporador de ar, curada a alta temperatura $\left(180\right.$ a $200^{\circ} \mathrm{C}$ ) e pressão (11 a 15 atmosferas). Dentre as suas propriedades destacam-se a baixa densidade $\left(0,3\right.$ a $\left.1,0 \mathrm{~g} / \mathrm{m}^{3}\right)$, resistência mecânica de 3 a $6 \mathrm{MPa}$, baixa condutividade e trabalhabilidade semelhante à madeira (SHORT \& KINNIBURG, 1978; CEB, 1978).

A química do processo de formação de tobermorita fundamenta-se na reação entre o cálcio e a sílica provenientes da hidratação dos silicatos cálcicos do cimento, complementada pela adição de cal e material silicioso (quartzo, pumicito, cinzas volantes, etc.).

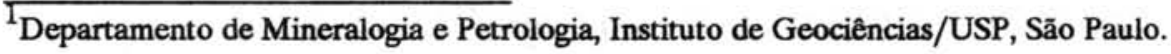


A cinética de reação depende da relação molar $\mathrm{CaO} / \mathrm{SiO}_{2}$, da finura dos materiais de partida, da natureza dos materiais silicosos, do tempo de reação (cristalização) e das condições de cura hidrotermal (TAYLOR, 1960; KALOUSEK, 1968).

O estudo da cinética de reação e das condições de formação e cristalização de tobermorita sintética, fundamentado na microestrutura e composição mineralógica de concretos celulares autoclavados constitui o objetivo desta pesquisa.

A parte analítica está sendo realizada com 12 amostras experimentais e industriais, utilizando-se das técnicas de difratometria de raios X, análises térmicas (ATD-TG) e microscopia eletrônica de varredura.

$\mathrm{A}$ análise por difratometria de raios $\mathrm{X}$ revelou composição similar entre as amostras. A tobermorita de $11 \AA$, principal produto de reação, e o quartzo residual constituem as fases principais. Subordinadamente, em proporções variadas, ocorrem C-S-H (I), calcita, vaterita, dolomita, portlandita, mica e clorita. Não foi constatada a presença de fases de alta temperatura (xonotlita e hillebrandita) e nem de fases com alta relação $\mathrm{CaO} / \mathrm{SiO}_{2}$. Estudos comparativos fundamentados nas relações de intensidades entre as raias do quartzo (100 e 201) e tobermorita $(002,220,040$ e 427$)$ permitiram avaliar o grau de cristalinidade da tobermorita e a freqüência de quartzo residual nas amostras.

A análise termodiferencial e termogravimétrica das amostras permitiu estudar o comportamento térmico, bem como estimar o conteúdo de quartzo residual e de tobermorita, fundamentado no pico endométrico a $575^{\circ} \mathrm{C}$ decorrente da transformação de quartzo $\alpha-\beta$ e no pico exotérmico à $826^{\circ} \mathrm{C}$ da tobermorita (Fig. 5).

A análise por microscopia eletrônica de varredura (MEV) permitiu o estudo da morfologia e microestrutura dos cristais de tobermorita, bem como de sua relação com os grãos de quartzo residual. As imagens obtidas por MEV revelam que os cristais de tobermorita são preferencialmente tabulares e alongados (Fig. 1), formando agregados cristalinos justapostos, sem orientação preferencial (Fig. 2). A presença de grãos de quartzo residual é relativamente comum e de freqüência variada entre as amostras. Caracterizam-se por não apresentarem bordas de reação na superfície dos grãos. A região de interface entre o grão de quartzo e a de cristalização da tobermorita é descontínua (Figs. 3 e 4) com orientação da cristalização da tobermorita, perpendicular à superfície dos grãos (Fig. 5).

As características e propriedades do concreto celular autoclavado dependem da natureza das fases formadas, distribuição de vazios, do grau de cristalização e da microestrutura desenvolvida pelos cristais de tobermorita. A cinética de reação de formação de tobermorita e a definição de parâmetros mineralógicos que permitam atuar no controle de 
qualidade e no desenvolvimento tecnologico do material são temas em investigação.

\section{REFERÊNCIAS BIBLIOGRÁFICAS}

CLARINGBULL, G.F. \& HEY, M.H. (1953) A re-examination of tobermorite. Mineralogical Magazine, 29:960-962.

McCONNELL, J.D.C. (1954) The hydrate calcium silicate riversideit, tobermorite and plombierite. Mineralogical Magazine, 30:293-305.

RAMACHANDRAN, V.S. (1965) Applications of differential thermal analysis in Cement Chemistry. New York, Chemical Publishing Company. 308p.

SHORT, A. \& KINNIBURGH, W. (1978) Lightweight concrete. Chap. 17: Aerated concrete manufacture and properties. London, Aplied Science Publishers Ltd.

COMITÉ EURO-INTERNATIONAL DU BÉTON (CEB) (1978) Autoclaved aerated concrete. Lancaster, The Construction Press Ltd.

TAYLOR, H.F.W. (1960) Hydrotermal reactions in the system $\mathrm{CaO}-\mathrm{SiO}_{2}-\mathrm{H}_{2} \mathrm{O}$ and the steam curing of cement and silica products. In: INTERNATIONAL SYMPOSIUM ON THE CHEMISTRY OF CEMENT,4., Washington, 1960. Proceedings. Washimgton. V.1, p.167-190.

KALOUSEK, G.L. (1968) Hight - Temperature steam curing of concrete at high pressure. In: INTERNATIONAL SYMPOSIUM ON THE CHEMISTRY OF CEMENT, 5., Tokyo, 1968. Proceedings. Tokyo. V.3, p.523-562. 


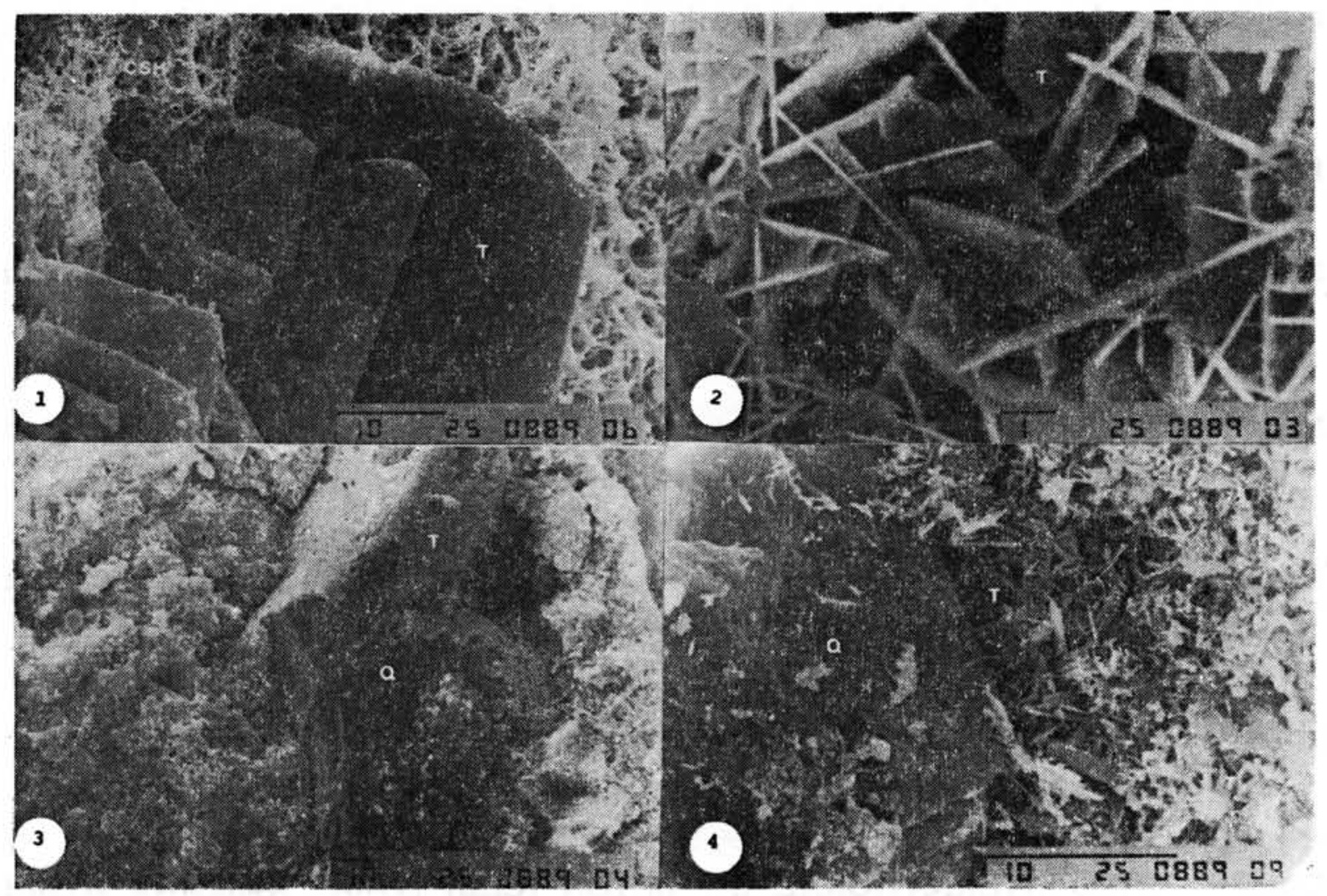

Figuras 1, 2, 3, e 4 - Cristais tabulares de tobermorita (T) junto a agregados mal cristalizados de silicato de calcio hidratado (CSH) de forma rendilhada (Fig. 1). Textura caracteristica formada pelos cristais tabulares de tobermorita no concreto celular autoclavado (Fig. 2). Grão de quartzo (Q) residual, sem borda de reaçăo, com cristalizaçăo de tobermorita na superfície (Fig. 3). Detalhe do grão de quartzo com cristalizaçăo de tobermorita perpendicular à superfície do grão.

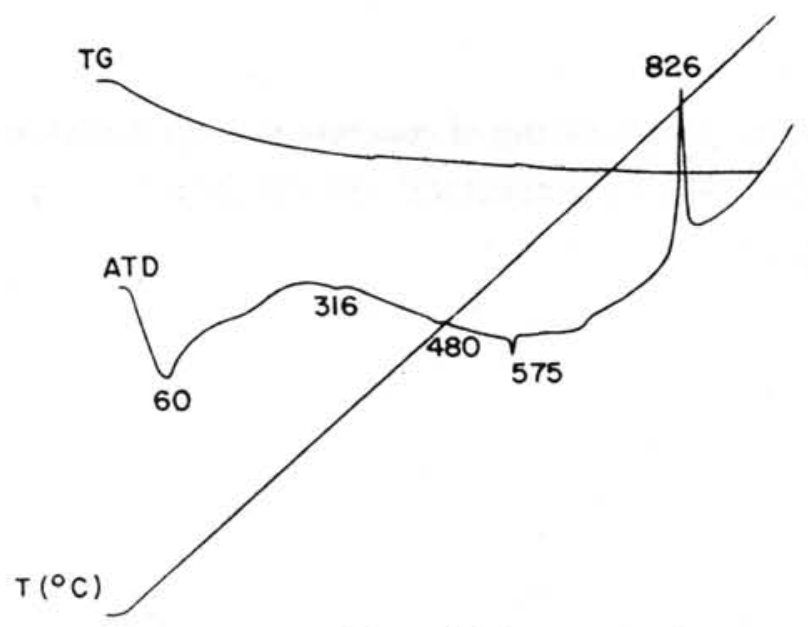

TG- curva termogravimétrica ATD - curva termodiferencial T - curva de temperatura

Figura 5 - Termograma de concreto celular autoclavado. 